\title{
Association between cognitive function and parameters of echocardiography and coronary artery angiography
}

\author{
Associação entre a função cognitiva e parâmetros de ecocardiografia e angiografia da \\ artéria coronária \\ Mohammad Hashemi', Zahra Teimouri Jervekani², Shahrzad Mortazavi3 , Mohammad Reza Maracy \\ Majid Barekatain ${ }^{5}$
}

\begin{abstract}
We aimed to determine whether there is an association between cognition and the results of echocardiography and angiography, based on neuropsychological assessments. Methods: We assessed the cognition of 85 patients who had recently undergone coronary artery angiography. We calculated the Gensini score for the coronary artery disease index. We also performed echocardiography to find indices of cardiac functioning. Results: The lower left ventricular ejection fraction correlated with lower scores on visuospatial, executive function, processing speed/attention and verbal memory capacities ( $p \leq 0.05$ ). A higher Gensini score and left atrial size correlated with lower executive function and processing speed/ attention $(p \leq 0.05$ ). In the group of patients with an impaired cognitive state, higher Gensini scores correlated with decreased processing speed/ attention ( $p=0.01$ ) and the e' index was associated with lower capacity of executive function ( $p=0.05)$. Conclusion: Decreased processing speed/ attention and executive function may correlate with cardiac dysfunction and coronary artery disease. The Color Trail Test may be considered for simple screening for cognitive problems in elderly patients with coronary artery disease or diastolic dysfunction.
\end{abstract}

Keywords: cognition; coronary artery disease; echocardiography; left ventricular function.

RESUMO

O objetivo deste estudo é encontrar associação entre cognição e resultados de exames ecocardiográficos e angiográficos, com base em avaliações neuropsicológicas. Método: Foi avaliada a cognição de 85 pacientes que foram submetidos a angiografia coronária. 0 escore de Gensini foi calculado para o índice de doença arterial coronariana (DAC). Foi realizado também, o exame ecocardiográfico a fim de descobrir os índices de funcionamento cardíaco. Resultados: A fração de ejeção do ventrículo inferior esquerdo está correlacionada com a baixa pontuação na capacidade visual e espacial, função executiva, velocidade de processamento/atenção e memória verbal ( $p \leq 0,05$ ). Alto escore de Gensini e tamanho do átrio esquerdo correlacionados com baixa função executiva, velocidade de processamento/atenção $(p \leq 0,05)$. No grupo de pacientes com estado cognitivo prejudicado, alto escore de Gensini correlacionado com diminuição da velocidade de processamento/atenção $(p=0,01)$ e índice e' associado a baixa capacidade da função executiva $(p=0,05)$. Conclusão: Diminuição da velocidade de processamento/atenção e da função executiva pode estar correlacionado a disfunção cardíaca e DAC. 0 Color Trail Test pode ser considerado para uma triagem simples de problemas cognitivos em pacientes idosos com DAC ou disfunção diastólica.

Palavras-chave: cognição; doença da artéria coronariana; ecocardiografia; função ventricular esquerda.

It has been estimated that the elderly population will rise from $7 \%$ in 2007 to $22 \%$ in $2050^{1}$. Progressive cognitive decline, which may become dementia, is one of the most important health problems in old age ${ }^{1}$. From the first neurocognitive sign to obvious dementia, there is usually a long transitional period with a broad range of presentations. This transitional period may have unremarkable signs of neurodegeneration without any clinically significant symptoms (predementia state) ${ }^{2}$. Elucidating

${ }^{1}$ Isfahan University of Medical Sciences, Interventional Research Center, Cardiovascular Department, Isfahan, Iran;

${ }^{2}$ Isfahan University of Medical Sciences, Heart Failure Research Center, Cardiovascular Department, Isfahan, Iran;

${ }^{3}$ Isfahan University of Medical Sciences, Psychiatry Department, Isfahan, Iran;

${ }^{4}$ Isfahan University of Medical Sciences, Department of Epidemiology and Biostatics, Isfahan, Iran;

5Isfahan University of Medical Sciences, Psychosomatic Research Center, Psychiatry Department, Isfahan, Iran.

Correspondence: Majid Barekatain; Psychosomatic Research Center, Nour Hospital, Ostandari Street, Isfahan, Iran; Post Code: 81458-31451; Email:

majidbarekatain1968@gmail.com

Conflict of interest: There is no conflict of interest to declare.

Received 21 October 2017, Received in final form 23 December 2017, Accepted 22 January 2018. 
risk factors for possible impending dementia can help with the design of preventive strategies and specific managements ${ }^{3}$.

Vascular risk factors including hypertension, diabetes mellitus, and hyperlipidemia are also prevalent in the elderly population, which can lead to higher incidences of cerebrovascular accidents and myocardial infarction ${ }^{4}$. These factors may also carry some risk for neurodegeneration, even in situations where cerebrovascular accidents and myocardial infarction are absent ${ }^{5}$. For example, coronary artery disease has been found to be an independent risk factor for vascular dementia ${ }^{4,5,6}$. A review study reported that heart failure also correlated with decreased memory registration, delayed free recall, working memory, executive function, and speed of information processing. Among the various cognitive domains, language and visuospatial performance were less affected by heart failure?

Although some studies have tried to evaluate the relationship between clinical presentations of ischemic heart disease and cognitive functioning, few studies have used a definitive index of coronary artery disease for this purpose ${ }^{8}$. Precise echocardiographic findings, including left ventricular systolic and diastolic indices, left atrial morphologic parameters, cardiac output and aortic root diameter, were used to show correlation between cognitive functioning and echocardiographic indices ${ }^{9}$. Regarding methods of cognitive evaluation, there have been a few studies that specifically administered neuropsychological tests to determine cognitive performance ${ }^{10,11}$.

In this study, we sought to find an association between cognitive functioning and specific parameters of cardiac echocardiography and coronary artery angiography. In addition, for a thorough evaluation of the cognitive profile, we used not only a neuropsychiatric screening tool but also specific neuropsychological tests to obtain objective measurements for each cognitive domain.

\section{METHODS}

\section{Study design and participants}

This study was approved by the Regional Bioethics Committee of Isfahan University of Medical Sciences. We discussed this project with all of the participants and obtained written informed consents.

Participants in this prospective study were the patients who underwent elective coronary artery angiography at Sina and Chamran hospitals' cardiac catheterization facilities in Isfahan, Iran in 2016. The inclusion criteria were: age 60 years or older, and education of primary school or higher levels. The participants were referred during the four weeks after elective coronary artery angiography for possible ischemic heart disease. We screened for those fitting the inclusion criteria through telephone calls. Based on their medical documents and hospital records, patients with a history of coronary artery bypass graft or percutaneous coronary angioplasty, head trauma, serious medical or neurological diseases, major psychiatric disorders, substance or medication-related disorders, and dementia were not included. The included participants underwent a semi-structured neuropsychiatry interview, assessments for cognitive functioning with specific neuropsychological tests, and echocardiography. Patients who could not perform the neuropsychological tests were excluded from the study. Baseline characteristics including age, gender, educational level, weight, height, smoking and alcohol use, medical history of stroke, diabetes mellitus, hypertension, hyperlipidemia, hypo/hyperthyroidism, and current drugs were recorded. Specific laboratory tests were also investigated.

\section{Cognitive assessments}

The Neuropsychiatry Unit Cognitive Assessment Tool (NUCOG) was used to evaluate the patients' cognitive function in the following domains: attention, visuospatial, memory, executive function, and language. The maximum score for each domain was 20 (with a total score of 100). In the Persian version of the NUCOG, the cutoff points for separating mild cognitive impairment from normal individuals and patients with dementia were 86.5 and 75 respectively. The Tower of London (TOL) test was selected to assess deficits in planning and set shifting of executive functioning. The Color Trail Test (CTT) was used for evaluation of processing speed/attention in CTT-part 1 and divided attention and executive function in CTT-part $2^{12}$. Verbal memory was assessed, using the Auditory Verbal Learning Test (AVLT) ${ }^{13}$. Two sets of tasks were used to assess language function, including the Persian Picture Naming Battery ${ }^{14}$ and the Persian Diagnostic Aphasia Battery ${ }^{15}$. These tests were administered by a well-trained neuropsychologist.

\section{Evaluation of cardiac function}

Two-dimensional echocardiography, with a GE Vivid 3 echocardiography device (General Electric Company, Milwaukee, WI, USA), was performed according to the American Society of Echocardiography standards, by a cardiology resident who was blinded to the neuropsychiatric tests. The selected parameters included left ventricular ejection fraction using the volume method and visual estimation. Indices of diastolic function on the basis of the peak mitral inflow velocity of the early rapid filling wave (E) and late filling wave caused by atrial contraction (A) and myocardial peak early velocity (e') from septal mitral annulus tissue doppler images were obtained, and the E/e' ratio was calculated. To assess the left atrial size, the end-systolic anteroposterior diameter in long axis view and the end-systolic left atrial surface area in 4-chamber view were measured ${ }^{16}$. Coronary artery angiography records were reviewed. The Gensini score was calculated by multiplying the severity of stenosis by the segment location and collateral adjustment factor. Higher scores in the Gensini indicated more severe coronary artery disease ${ }^{17}$. 


\section{Statistical analysis}

All statistical analyses were carried out using the SPSS 18 (SPSS crop. Chicago, IL, USA). Quantitative and qualitative variables were calculated as mean \pm standard deviation and proportion in percentage, respectively. Pearson's correlation was used to identify the strength and direction of any correlation between cardiac and cognitive quantitative variables with statistical significance level $p \leq 0.05$. Based on the NUCOG cutoff point of 86, patients were divided into two categories (normal and impaired cognition) to compare demographic, clinical and neuropsychological variables. The association between the cardiovascular parameters and cognitive variables were also evaluated, using Multivariate Analysis of Variance, which was adjusted for potential confounders.

\section{RESULTS}

Of 153 referred patients, 60 did not meet the full inclusion criteria and eight individuals were excluded due to their refusal to participate or inability to perform the tests. A total of 85 patients were enrolled in the study. Table 1 shows the baseline characteristics and statistical measures. The mean sample age was $65.78 \pm 5.13$ and $85.9 \%$ were men. The NUCOG score average was $80.56 \pm 8.30$.

Considering all the patients in a group, the correlation of echocardiography and angiography indices with NUCOG scores, CTT, and AVLT tests are shown in Table 2. The left ventricular ejection fraction was positively correlated with the NUCOG score $(\mathrm{P}=0.005, \mathrm{R}=0.30)$, CTT-parts 1 and 2 ( $\mathrm{p}=0.02, \mathrm{R}=0.024$ and $\mathrm{p}=0.01, \mathrm{R}=0.27$ ), AVLT $5^{\text {th }}$ trial and after 30 minutes $(p=0.03, R=0.23$ and $p=0.01, R=0.26)$. The left atrial area and dimension were positively correlated with CTT tests as shown in Table 2, and higher Gensini scores were also associated with higher CTT-times 1 and 2 $(\mathrm{p}=0.001, \mathrm{R}=0.35$ and $\mathrm{p}=0.01, \mathrm{R}=0.27$ ).

In addition, there was a positive correlation between the left atrial diameter and area with the TOL-time $(\mathrm{p}=0.003$, $\mathrm{R}=0.32$ and $\mathrm{P}=0.001, \mathrm{R}=0.34$ respectively). No association was found between other cardiac indices and cognitive measures $(p>0.5)$

On the NUCOG cutoff, patients were divided into normal individuals and patients with impaired cognition. Of the latter, $73 \%$ had an abnormal NUCOG score and $84 \%$ were men in this group. Using Multivariate Analysis of Variance with age and sex adjustment, there was a positive association between the Gensini score and CTT-time $1(\mathrm{P}=0.01, \mathrm{SE}=0.26$ and $95 \%$ CI $[0.05,0.47])$ in patients with impaired cognition. The e' as an index of diastolic function was negatively correlated with CTT-time $2(p=0.05, \mathrm{SE}=6.52$ and $95 \% \mathrm{CI}[-2.53,0.00])$ in the same group. There was a negative correlation between the e' and AVLT immediate free recall of the $5^{\text {th }}$ trial in the normal cognition group ( $p=0.04, \mathrm{SE}=0.003,95 \% \mathrm{CI}[-0.001,0.00]$ ). Other data are summarized in Table 3.
Table 1. Demographic characteristics and clinical and biochemical parameters of the study population.

\begin{tabular}{|c|c|}
\hline Clinical variables & $\mathrm{n}$ (percentage) mean $\pm \mathrm{SD}$ \\
\hline \multicolumn{2}{|l|}{ Demographic features } \\
\hline Age & $65.78 \pm 5.13$ \\
\hline Male gender (\%) & $73(85.9)$ \\
\hline \multicolumn{2}{|l|}{ Education: } \\
\hline $5-8$ years & $30(35.3)$ \\
\hline $9-12$ years & $27(31.8)$ \\
\hline$>12$ years & $28(32.9)$ \\
\hline History of smoking (\%) & $33(38.3)$ \\
\hline $\mathrm{BMI}$ & $25.16 \pm 3.31$ \\
\hline \multicolumn{2}{|l|}{ Medical history } \\
\hline Diabetes mellitus (\%) & $25(29.4)$ \\
\hline Hypertension (\%) & $34(40)$ \\
\hline CVA (\%) & $6(7.1)$ \\
\hline Hypothyroidism (\%) & $5(5.9)$ \\
\hline History of smoking (\%) & $33(38.3)$ \\
\hline \multicolumn{2}{|l|}{ Laboratory data } \\
\hline Fasting plasma glucose (mg/dl) & $109.49 \pm 28.85$ \\
\hline $\mathrm{HbA} 1 \mathrm{C}(\%)$ & $6.27 \pm 1.56$ \\
\hline Total cholesterol (mg/dl) & $151.42 \pm 32.54$ \\
\hline Triglycerides (mg/dl) & $144.63 \pm 69.18$ \\
\hline $\mathrm{HDL}(\mathrm{mg} / \mathrm{dl})$ & $41.84 \pm 8.97$ \\
\hline LDL (mg/dl) & $86.66 \pm 64.58$ \\
\hline Creatinine (mg/dl) & $1.14 \pm 0.39$ \\
\hline \multicolumn{2}{|l|}{ Cognitive measures } \\
\hline NUCOG total score & $80.56 \pm 8.30$ \\
\hline NUCOG A (attention) & $13.32 \pm 2.67$ \\
\hline NUCOG B (visuospatial) & $17.62 \pm 2.10$ \\
\hline NUCOG C (memory) & $14.46 \pm 2.68$ \\
\hline NUCOG D (executive function) & $15.64 \pm 3.09$ \\
\hline NUCOG E (language) & $19.37 \pm 1.10$ \\
\hline CTT-time 1 & $99.23 \pm 38.22$ \\
\hline CTT-time 2 & $208.62 \pm 88.07$ \\
\hline TOL-score & $34.81 \pm 1.49$ \\
\hline TOL-time & $286.08 \pm 74.96$ \\
\hline P-DAB (AQ) & $94.81 \pm 3.11$ \\
\hline P-PNB-score & $47.24 \pm 7.17$ \\
\hline P-PNB-time & $139.8 \pm 67.6$ \\
\hline AVLT (5 $5^{\text {th }}$ trial) & $9.52 \pm 2.4$ \\
\hline AVLT (after 30 minutes) & $6.56 \pm 2.91$ \\
\hline \multicolumn{2}{|l|}{ Echocardiography measures } \\
\hline $\operatorname{LVEF}(\%)$ & $54.94 \pm 8.36$ \\
\hline$E(\mathrm{~m} / \mathrm{s})$ & $0.67 \pm 0.17$ \\
\hline$A(m / s)$ & $0.83 \pm 0.16$ \\
\hline$E / A$ & $0.83 \pm 0.24$ \\
\hline$e^{\prime}(m / s)$ & $0.06 \pm 0.01$ \\
\hline E/e' & $11.04 \pm 3.28$ \\
\hline LA diameter $(\mathrm{cm})$ & $3.46 \pm 0.47$ \\
\hline LA area $\left(\mathrm{cm}^{2}\right)$ & $15.28 \pm 3.71$ \\
\hline Gensini Score & $36.20 \pm 23.86$ \\
\hline
\end{tabular}

Data are presented as mean \pm SD and $n$ (\%). BMI: body mass index; CVA: cerebrovascular accident; HDL: high density lipoprotein; LDL: low density lipoprotein; NUCOG: Neuropsychiatry unit cognitive assessment tool; CTT: Color trail test; TOL: Tower of London test; P-DAB: Persian diagnostic aphasia battery; P-PNB: Persian picture naming battery; AVLT: Auditory verbal learning test; LVEF: left ventricular ejection fraction; E: early mitral valve flow velocity; A: late mitral valve flow velocity; e': diastolic lengthening velocity; LA: left atrial. 
Table 2. Correlation of cardiac parameters with cognitive tasks.

\begin{tabular}{|c|c|c|c|c|c|c|c|c|c|c|c|c|c|c|}
\hline \multirow{2}{*}{ Variable } & \multicolumn{2}{|c|}{ Gensini score } & \multicolumn{2}{|c|}{ LVEF (\%) } & \multicolumn{2}{|c|}{$\operatorname{LAD}(\mathrm{cm})$} & \multicolumn{2}{|c|}{ LA area $\left(\mathrm{cm}^{2}\right)$} & \multicolumn{2}{|c|}{$E(m / s)$} & \multicolumn{2}{|c|}{$e^{\prime}(m / s)$} & \multicolumn{2}{|c|}{$E / e^{\prime}$} \\
\hline & $\mathrm{R}$ & $p$ & $\mathrm{R}$ & $p$ & $\mathrm{R}$ & $p$ & $\mathrm{R}$ & $p$ & $\mathrm{R}$ & $p$ & $\mathrm{R}$ & $\mathrm{p}$ & $\mathrm{R}$ & $\mathrm{P}$ \\
\hline NUCOG-total & -0.10 & 0.33 & 0.30 & 0.005 & -0.11 & 0.27 & -0.18 & 0.09 & 0.003 & 0.98 & -0.007 & 0.95 & -0.04 & 0.66 \\
\hline A (attention) & -0.12 & 0.25 & 0.18 & 0.9 & -0.02 & 0.79 & -0.2 & 0.06 & -0.08 & 0.42 & -0.07 & 0.52 & -0.04 & 0.7 \\
\hline B (visuospatial) & -0.16 & 0.13 & 0.23 & 0.03 & -0.03 & 0.76 & -0.03 & 0.77 & -0.004 & 0.97 & 0.05 & 0.6 & -0.12 & 0.27 \\
\hline C (memory) & 0.0 & 0.99 & 0.18 & 0.08 & -0.18 & 0.08 & -0.17 & 0.10 & -0.05 & 0.59 & 0.03 & 0.72 & -0.11 & 0.30 \\
\hline D (executive function) & -0.04 & 0.68 & 0.26 & 0.01 & -0.11 & 0.28 & -0.16 & 0.14 & 0.1 & 0.34 & -0.04 & 0.66 & 0.10 & 0.34 \\
\hline E (language) & -0.04 & 0.70 & 0.16 & 0.14 & -0.01 & 0.86 & 0.002 & 0.98 & 0.06 & 0.57 & 0.09 & 0.4 & -0.11 & 0.29 \\
\hline CTT-time 1 & 0.35 & 0.001 & -0.24 & 0.02 & 0.28 & 0.008 & 0.28 & 0.008 & 0.12 & 0.27 & -0.01 & 0.89 & 0.11 & 0.31 \\
\hline CTT-time 2 & 0.22 & 0.03 & -0.27 & 0.01 & 0.2 & 0.06 & 0.25 & 0.01 & 0.1 & 0.36 & 0.11 & 0.31 & 0.01 & 0.88 \\
\hline AVLT (5 $5^{\text {th }}$ trial) & -0.03 & 0.74 & 0.23 & 0.03 & -0.09 & 0.4 & -0.2 & 0.06 & -0.03 & 0.74 & -0.03 & 0.74 & 0.03 & 0.74 \\
\hline AVLT (30 minutes) & -0.1 & 0.32 & 0.26 & 0.01 & -0.03 & 0.74 & -0.06 & 0.56 & -0.01 & 0.89 & -0.04 & 0.71 & 0.07 & 0.50 \\
\hline
\end{tabular}

NUCOG: Neuropsychiatry unit cognitive assessment tool; CTT: Color trail test; AVLT: Auditory verbal learning test; LVEF: left ventricular ejection fraction; E: early mitral valve flow velocity; e': diastolic lengthening velocity; LA: left atrial; LAD: Left Atrial Diameter.

Table 3. Age and sex adjusted associations between echocardiography and coronary artery angiography measures and cognitive functioning using Multivariate Analysis of Variance (MANOVA).

\begin{tabular}{|c|c|c|c|c|c|c|c|c|c|c|c|c|c|c|c|c|}
\hline \multirow{2}{*}{ Variable } & \multicolumn{8}{|c|}{ Impaired cognition } & \multicolumn{8}{|c|}{ Normal Cognition } \\
\hline & \multicolumn{8}{|c|}{ Based on NUCOG $<86$} & \multicolumn{8}{|c|}{ Based on NUCOG $\geq 86$} \\
\hline Number (\%) & \multicolumn{8}{|c|}{$62(72.94)$} & \multicolumn{8}{|c|}{$23(27.05)$} \\
\hline Age & \multicolumn{8}{|c|}{$66.06 \pm 5.22$} & \multicolumn{8}{|c|}{$65.00 \pm 4.90$} \\
\hline Male (\%) & \multicolumn{8}{|c|}{$5(83.87)$} & \multicolumn{8}{|c|}{$19(82.60)$} \\
\hline \multirow[t]{2}{*}{ Effect } & \multicolumn{2}{|c|}{ CTT-time 1} & \multicolumn{2}{|c|}{ CTT-time 2} & \multicolumn{2}{|c|}{$\begin{array}{c}\text { AVLT } \\
\text { (5th trial) }\end{array}$} & \multicolumn{2}{|c|}{$\begin{array}{c}\text { AVLT } \\
\text { (30 minutes) }\end{array}$} & \multicolumn{2}{|c|}{ CTT-time 1} & \multicolumn{2}{|c|}{ CTT-time 2} & \multicolumn{2}{|c|}{$\begin{array}{c}\text { AVLT } \\
\left(5^{\text {th }} \text { trial }\right)\end{array}$} & \multicolumn{2}{|c|}{$\begin{array}{c}\text { AVLT } \\
\text { (30 minutes) }\end{array}$} \\
\hline & $\mathrm{p}$ & $\mathrm{t}$ & $\mathrm{p}$ & $\mathrm{t}$ & $\mathrm{p}$ & $\mathrm{t}$ & $\mathrm{p}$ & $\mathrm{t}$ & $\mathrm{p}$ & $\mathrm{t}$ & $\mathrm{p}$ & $\mathrm{t}$ & $p$ & $\mathrm{t}$ & $\mathrm{p}$ & $\mathrm{t}$ \\
\hline Gensini score & 0.01 & 2.53 & 0.50 & 0.66 & 0.11 & 1.59 & 0.47 & -0.72 & 0.51 & 0.67 & 0.36 & 0.92 & 0.88 & -0.14 & 0.48 & 0.70 \\
\hline LVEF (\%) & 0.16 & -1.14 & 0.28 & -1.07 & 0.55 & -0.59 & 0.31 & 1.01 & 0.55 & -0.60 & 0.26 & 1.17 & 0.16 & -1.45 & 0.80 & 0.24 \\
\hline LA diameter (cm) & 0.20 & 1.18 & 0.23 & 1.13 & 0.97 & 0.03 & 0.82 & 0.22 & 0.31 & 1.03 & 0.57 & -0.56 & 0.76 & -0.30 & 0.51 & 0.67 \\
\hline LA area $\left(\mathrm{cm}^{2}\right)$ & 0.24 & 1.18 & 0.17 & 1.37 & 0.45 & -0.74 & 0.70 & 0.37 & 0.89 & 0.13 & 0.77 & 0.27 & 0.32 & -1.02 & 0.17 & 1.43 \\
\hline$E(m / s)$ & 0.17 & 1.37 & 0.94 & -0.07 & 0.94 & -0.07 & 0.88 & -0.14 & 0.90 & 0.11 & 0.66 & -0.44 & 0.52 & 0.65 & 0.41 & -0.84 \\
\hline$e^{\prime}(\mathrm{m} / \mathrm{s})$ & 0.46 & -0.74 & 0.05 & 1.93 & 0.59 & 0.53 & 0.73 & -0.33 & 0.97 & 0.03 & 0.80 & 0.24 & 0.04 & -2.17 & 0.52 & -0.64 \\
\hline
\end{tabular}

NUCOG: Neuropsychiatry Unit COGNITIVE ASSESSMENT TOOL; CTT: Color TRAIL TEST; AVLT: Auditory VERBAL LEARNING TEST; LVEF: left ventricular ejection fraction; E: early mitral valve flow velocity; e': diastolic lengthening velocity; LA: left atrial.

\section{DISCUSSION}

In this study, we investigated the relationship between echocardiography and coronary artery angiography parameters; and cognitive function, using a neuropsychiatric screening tool and precise neuropsychological tests.

We found that the ejection fraction, as the index of cardiac systolic function, was significantly correlated with global cognition, based on the total NUCOG scores $(p=0.005)$. Considering distinct cognitive domains of the NUCOG, the ejection fraction was correlated with visuospatial (NUCOG subscale B) $(p=0.03)$ and executive function (NUCOG subscale $D)(p=0.01)$. It was also associated with processing speed/attention $(p=0.02)$ in the CTT-part 1 and divided attention and executive function in the CTT-part $2(p=0.01)$.
In a prospective study on 44 elderly outpatients with documented heart failure, scores less than 26 on the Montreal Cognitive Assessment were detected in more than $70 \%$ of the patients $^{18}$. In a systematic review, Vogels et al. ${ }^{19}$ compared the risk of cognitive impairment in a pooled sample of 2,937 heart failure patients with 14,848 controls. They found that the risk of cognitive impairment was 1.62 greater in the heart failure group. They also reported that diminished performance of psychomotor speed/attention (assessed using the Trail Making Test-A) was correlated with heart failure ${ }^{19}$. Athilingam et al. reported that the mean Montreal Cognitive Assessment score was lower in patients with systolic heart failure than diastolic failure, especially in the visuospatial ability, psychomotor speed, and executive function domains ${ }^{20}$. In contrast to these reports, Park et al. showed that there was no association between "peak velocities 
during systole" and cognitive function; however, left ventricular diastolic function had strong association with global cognition, which was assessed with "a community screening instrument for dementia" ${ }^{\prime 1}$. Visual memory and processing speed had also a significant association with left ventricular global function. They reported that left ventricular diastolic function correlated with working memory and fluency of speech ${ }^{21}$. Although, we could not find the same results for diastolic dysfunction in the total sample of our study, there was significant relationship between e' and immediate free recall of verbal learning $(p=0.04)$ in patients with a total NUCOG score of 86 or more.

Although the exact mechanisms explaining the link between systolic dysfunction and cognitive decline remain unknown, improvement of cardiac output by cardiac transplantation and resynchronization therapy has often resulted in better cognitive functioning ${ }^{22,23}$. Cerebral hypoperfusion, silent cerebral infarction, impaired cerebrovascular autoregulation, atrial fibrillation, and endothelial dysfunction have been suggested mechanisms for decreasing cognitive performance in heart failure ${ }^{11}$. Interestingly, patients in our study had mean ejection fraction scores of $54.94 \pm 8.36$, which could be considered as preserved ejection fraction (or mild reduction: $45<$ ejection fraction $<55)^{16}$. It means that even slight reduction of the ejection fraction may lead to significant cognitive changes. In a longitudinal nondemented population-based study with echocardiography assessments at baseline and after five years follow up, van den Hurk et al. concluded that cognitive decline can be observed in the early stages of left ventricular dysfunction and heart failure ${ }^{11}$. It seems that from the above-mentioned mechanisms, impaired cerebrovascular autoregulation and endothelial dysfunction are possibly more affected with even mild reduction of the ejection fraction ${ }^{24}$.

Our patients were selected from referrals to a cardiac catheterization unit. Logically, it might be hypothesized that the main contributor of ejection fraction reduction in most of them was ischemic events (as we found regional wall motion abnormality during echocardiography). We concluded that the ischemia, not the reduced ejection fraction per se, could negatively affect cognition. We found significant correlation between the diastolic dysfunction index (e') with the CTTpart 2 in patients with impaired cognition (Table 3 ).

In our study, the Gensini score, as the index for severity of coronary artery disease, was significantly correlated with processing speed/attention ( $\mathrm{P}=0.001)$ of the CTT-part 1 and divided attention and executive function of the CTT-part $2(\mathrm{P}=0.03)$. When participants were divided into two distinct groups of patients with normal cognition and patients with impaired cognition (based on the NUCOG cutoff point), Gensini scores were significantly associated with the CTT-part 1.

In a cross-sectional study of postmenopausal women with a history of myocardial infarction, the prevalence of cognitive decline was double that of their counterparts without myocardial infarction ${ }^{25}$. In a case-control study on patients who had recently been admitted to cardiac catheterization facilities, Barekatain et al. showed that in patients with mild cognitive impairment, a greater degree of coronary stenosis correlated with a greater loss of gray matter in specific brain regions. However, they could not show this in the cognitively normal patients.

Vidal and colleagues, in their cross-sectional study, showed that lower scores on the speed of processing and executive function, but not memory, were strongly correlated with atherosclerotic burden, indirectly estimated by coronary artery calcium load, measured with CT scans ${ }^{26}$.

In our study, the left atrial surface area, which is a significant predictor of cardiovascular morbidity and mortality outcomes, was associated with processing speed/attention $(p=0.008)$ in the CTT-part 1, divided attention/executive function of CTTpart $2(p=0.01)$, and the TOL-time $(p=0.001)$. In one study on 108 healthy people without cardiovascular disease, a larger left atrium was associated with cognitive impairment based on the Mini-Mental State Examination ${ }^{27}$. In a study by van den Hurk et al., the left atrial volume index was specifically correlated with a lower speed of information processing ${ }^{11}$. An enlarged left atrium may have a possible risk for thrombogenesis due to blood stasis. This can result in a propensity for microembolization in cerebral arteries, which in turn may have adverse effects on cognition ${ }^{27}$. In addition to possible consequences of left atrial enlargement, comorbidities such as hypertension, left ventricular dysfunction, and coronary artery disease may also be responsible for cognitive impairment ${ }^{27}$.

On the other hand, left atrial enlargement may be an adaptive response to endothelial dysfunction ${ }^{28}$. Thus, it may indirectly point to one of the possible mechanisms of the brain degenerative process ${ }^{28}$.

Assessment of memory in the patients in the present study showed that the AVLT- $5^{\text {th }}$ trial (indicator of immediate recall) ( $p=0.03$ ) and the AVLT-free delayed recall (after 30 minutes) ( $p$ $=0.01$ ) had a significant correlation with the ejection fraction. In one study on 251 outpatients with stable heart failure, cognitive impairment was found in $58 \%$ of the sample. Immediate and delayed verbal memory was the most impaired cognitive domain ${ }^{29}$. The results of a study by Almeida et al. showed that adults with heart failure had a worse immediate and longterm memory and psychomotor speed than healthy controls. Another finding of their study of heart failure patients, was the loss of volume in the posterior association cortex, which plays an important role in the retrieval of memory $\mathrm{y}^{30}$.

\section{Limitations}

The most important limitation in this study was its small sample size, which does not permit generalization of the results. The overall cardiovascular risk factors in patients who were referred for catheterization were high. This might result in an underestimation of the effects, under powering the extrapolation of the study's results. This part of our study did not have a follow-up. Thus, the causal relationship between ischemic heart disease or left ventricular dysfunction and cognitive impairment could not be concluded. Although the duration of 
cardiac disease may also exaggerate the deterioration of cognition and could have been included, we did not have accurate and reliable data. Future studies based on a prospective cohort design should be performed to determine whether the cognitive deficits are due to heart disease or not.

In summary, we showed that decreased processing speed/attention and executive function may correlate with cardiac dysfunction and coronary artery disease. The prognostic implication of coronary artery disease and diastolic dysfunction in patients with possible cognitive impairment may be worse concomitantly, than in either alone. The CTT may be recommended as a simple screening test for cognitive problems in elderly patients with coronary artery disease or diastolic dysfunction.

\section{References}

1. Lutz W, Sanderson W, Scherbov S. The coming acceleration of global population ageing. Nature. 2008 Feb;451(7179):716-9. https://doi.org/10.1038/nature06516

2. Vos SJ, Xiong C, Visser PJ, Jasielec MS, Hassenstab J, Grant EA et al. Preclinical Alzheimer's disease and its outcome: a longitudinal cohort study. Lancet Neurol. 2013 Oct;12(10):957-65. https://doi.org/10.1016/S1474-4422(13)70194-7

3. Patterson C, Feightner JW, Garcia A, Hsiung GY, MacKnight C, Sadovnick AD. Diagnosis and treatment of dementia: 1. Risk assessment and primary prevention of Alzheimer disease. CMAJ. 2008 Feb;178(5):548-56. https://doi.org/10.1503/cmaj.070796

4. Paciaroni M, Bogousslavsky J. Connecting cardiovascular disease and dementia: further evidence. J Am Heart Assoc. 2013 Dec;2(6):e000656. https://doi.org/10.1161/JAHA.113.000656

5. Fillit $\mathrm{H}, \mathrm{Nash} \mathrm{DT}$, Rundek T, Zuckerman A. Cardiovascular risk factors and dementia. Am J Geriatr Pharmacother. 2008 Jun;6(2):100-18. https://doi.org/10.1016/j.amjopharm.2008.06.004

6. Siuda J, Gorzkowska A, Opala G, Ochudto S. Vascular risk factors and intensity of cognitive dysfunction in MCl.J Neurol Sci. 2007 Jun;257(1-2):202-5. https://doi.org/10.1016/j.jns.2007.01.034

7. Leto L, Feola M. Cognitive impairment in heart failure patients. J Geriatr Cardiol. 2014 Dec;11(4):316-28. https://doi.org/10.11909/j.issn.1671-5411.2014.04.007

8. Barekatain M, Askarpour $\mathrm{H}$, Zahedian F, Walterfang M, Velakoulis $D$, Maracy MR et al. The relationship between regional brain volumes and the extent of coronary artery disease in mild cognitive impairment. J Res Med Sci. 2014 Aug;19(8):739-45.

9. Arangalage D, Ederhy S, Dufour L, Joffre J, Van der Vynckt C, Lang $S$ et al. Relationship between cognitive impairment and echocardiographic parameters: a review. J Am Soc Echocardiogr. 2015 Mar;28(3):264-74. https://doi.org/10.1016/j.echo.2014.11.009

10. Kovacic JC, Castellano JM, Fuster V. The links between complex coronary disease, cerebrovascular disease, and degenerative brain disease. Ann NY Acad Sci. 2012 Apr;1254(1):99-105. https://doi.org/10.1111/j.1749-6632.2012.06482.x

11. van den Hurk K, Reijmer YD, van den Berg E, Alssema M, Nijpels G, Kostense PJ et al. Heart failure and cognitive function in the general population: the Hoorn Study. Eur J Heart Fail. 2011 Dec;13(12):1362-9. https://doi.org/10.1093/eurjhf/hfr138

12. Barekatain M, Alavirad M, Tavakoli M, Emsaki G, Maracy MR. Cognitive rehabilitation in patients with nonamnestic mild cognitive impairment. J Res Med Sci. 2016 Nov;21(1):101. https://doi.org/10.4103/1735-1995.193173

13. JafariZ,Steffen Moritz P,Zandi T,Aliakbari Kamrani A, Malyeri S. Psychometric properties of Persian version of the Rey Auditory-Verbal Learning Test (RAVLT) among the elderly. Iran J Psychiatry. 2010;16(1):56-64.

14. Nilipour R. Persian aphasia naming test. Tehran: University of Social Welfare and Rehabilitation Sciences; 2012.

15. Nilipour R, Pourshahbaz A, Ghoreyshi ZS. Reliability and validity of bedside version of Persian WAB (P-WAB-1). Basic Clin Neurosci. 2014 Oct;5(4):253-8.

16. Mann DL,Zipes DP, Libby P,Bonow RO. Braunwald's heart disease: a textbook of cardiovascular medicine. Philadelphia: Elsevier Health Sciences; 2014.
17. Gensini GG. A more meaningful scoring system for determining the severity of coronary heart disease. Am J Cardiol. 1983 Feb;51(3):606. https://doi.org/10.1016/S0002-9149(83)80105-2

18. Harkness K, Demers C, Heckman GA, McKelvie RS. Screening for cognitive deficits using the Montreal cognitive assessment tool in outpatients $\geq 65$ years of age with heart failure. Am J Cardiol. 2011 Apr;107(8):1203-7. https://doi.org/10.1016/j.amjcard.2010.12.021

19. Vogels RL, Scheltens P,Schroeder-Tanka JM, Weinstein HC. Cognitive impairment in heart failure: a systematic review of the literature. Eur J Heart Fail. 2007 May;9(5):440-9. https://doi.org/10.1016/j.ejheart.2006.11.001

20. Athilingam P, D’Aoust RF, Miller L, Chen L. Cognitive profile in persons with systolic and diastolic heart failure. Congest Heart Fail. 2013 Jan-Feb;19(1):44-50. https://doi.org/10.1111/chf.12001

21. Park CM, Williams ED, Chaturvedi N, Tillin T, Stewart RJ, Richards M et al. Associations between left ventricular dysfunction and brain structure and function: findings from the SABRE (Southall and Brent revisited) study. J Am Heart Assoc. 2017 Apr;6(4):e004898. https://doi.org/10.1161/JAHA.116.004898

22. Cupples SA, Stilley CS. Cognitive function in adult cardiothoracic transplant candidates and recipients.J Cardiovasc Nurs. 2005 Sep-Oct;20(5 Suppl):S74-87. https://doi.org/10.1097/00005082-200509001-00009

23. Hoth KF, Poppas A, Ellison KE, Paul RH, Sokobin A, Cho Y et al. Link between change in cognition and left ventricular function following cardiac resynchronization therapy.J Cardiopulm Rehabil Prev. 2010 Nov-Dec;30(6):401-8. https://doi.org/10.1097/HCR.0b013e3181e1739a

24. Caldas JR, Panerai RB, Haunton VJ, Almeida JP, Ferreira GS, Camara Let al. Cerebral blood flow autoregulation in ischemic heart failure. Am J Physiol Regul Integr Comp Physiol. 2017 Jan;312(1):R108-13. https://doi.org/10.1152/ajpregu.00361.2016

25. Haring B, Leng X, Robinson J, Johnson KC, Jackson RD, Beyth $R$ et al. Cardiovascular disease and cognitive decline in postmenopausal women: results from the Women's Health Initiative Memory Study. J Am Heart Assoc. 2013 Dec;2(6):e000369. https://doi.org/10.1161/JAHA.113.000369

26. Vidal JS, Sigurdsson S, Jonsdottir MK, Eiriksdottir G, Thorgeirsson G, Kjartansson $\mathrm{O}$ et al. Coronary artery calcium, brain function and structure: the AGES-Reykjavik Study. Stroke. 2010 May;41(5):891-7. https://doi.org/10.1161/STROKEAHA.110.579581

27. Karadag B, Ozyigit T, Ozben B, Kayaoglu S, Altuntas Y. Relationship between left atrial volume index and cognitive decline in elderly patients with sinus rhythm. J Clin Neurosci. 2013 Aug;20(8):1074-8. https://doi.org/10.1016/j.jocn.2012.10.021

28. Etgen T, Sander D, Bickel H, Förstl H. Mild cognitive impairment and dementia: the importance of modifiable risk factors. Dtsch Arztebl Int. 2011 Nov;108(44):743-50. https://doi.org/10.3238/arztebl.2011.0743

29. Hawkins LA, Kilian S, Firek A, Kashner TM, Firek CJ, Silvet H. Cognitive impairment and medication adherence in outpatients with heart failure. Heart Lung. 2012 Nov-Dec;41(6):572-82. https://doi.org/10.1016/j.hrtlng.2012.06.001

30. Almeida OP, Beer C, Lautenschlager NT, Arnolda L, Alfonso H, Flicker L. Two-year course of cognitive function and mood in adults with congestive heart failure and coronary artery disease: the Heart-Mind Study. Int Psychogeriatr. 2012 Jan;24(1):38-47. https://doi.org/10.1017/S1041610211001657 